\title{
Pedagogical Problem in Development of Artistic Taste via Fine Arts in Teenagers
}

\author{
Nodari Mirazanashvili \\ Gori State Teaching University, Gori, Georgia
}

\begin{abstract}
Fine and applied arts are one of the basic disciplines of the school subjects of the "aesthetic cycle" playing a great role in the formation of the personal qualities of teenagers. It plays an essential role in the development of personal character of a teenager. Its correct teaching has tremendous importance.

Observation of wide spectrum of constitutive components of esthetical consciousness proves that they have many joint and crosscutting points; among these components is the phenomenon of taste of art. Feeling as a condition of expression of esthetical approach may not advance and reach true esthetical feeling unless it undergoes sufficient regular practice.

It is known that esthetical evaluation, as a process itself, is preceded by the sufficient act of perception. Without perception it is not possible to evaluate as far as these two are logically interwoven.

Fine and Applied Arts have developed into an interesting phenomenon in many respects. Although it underwent a long pass of development the process has not been finished yet. A lot needs to be identified further. It is important to organize the researches which would impart new content to the process of development and for this purpose would uncover the reserves still existing in the form of interrelations of personal-psychological characteristics of a teenager and inner possibilities of fine arts, as a teaching discipline. A problem of development of artistic taste in teenagers should be presented within the system of esthetic education which needs a complex approach and consideration of its all basic parameters.
\end{abstract}

\section{Introduction}

Difficult sociopolitical processes taking place in the society following a total collapse of the Soviet Imperial structures affected each direction of life: economics, politics, culture and civil education.

As a result of global changes a harmful but irreversible process of re-apprising of material and spiritual values, demolishment of stereotypes, establishment of the new ethical ideals have occurred.

It is natural that a wave of change impacted the field of teenager education too. It turned out that because of bitter social experience and nonestablished philosophy of life, teenagers had difficulty to find orientation in absolutely strange developments. As a result, rapid demolishment of the dynamic stereotypes, disorientation of consciousness and negative personal features as aggression, cruelty, fattish of false values have occurred.

Critical characteristic of the situation revealed great importance of education system at school. One of the most important parts of the system is development of true values in teenagers via art.

Fine and applied arts are one of the basic disciplines of the school subjects of the "aesthetic cycle" playing a great role in the formation of the personal qualities of teenagers. Thus, its correct teaching has tremendous importance. Pupils in school and outside school often encounter specimens of fine arts. The press, journals, illustrated books, albums, exhibitions, museums, reflecting the work of painters separate monuments of culture provide certain aesthetic information to teenagers, at the same time affecting their views, perception, taste, and the system of aesthetic relations, in general. This process of encountering fine arts is not of course organized. For this reason, accumulation of artistic information by teenagers often has the spontaneous character, which 
leaves a peculiar imprint on the artistic-aesthetic development of pupils.

The ability of perception and evaluation of a work of art fails to be developed purposefully, which in its turn hampers the process of the formation of artistic taste. As a result of this, pupils do not become aware and do not understand the social-aesthetic function of art, the unity of the form and content of separate works, the peculiarities of the composition and style.

Art, as a form of social consciousness, reflecting and showing the world in its unity, has a profound effect on man, it imprints deeply on his consciousness, sensual-emotional world. Proceeding from this, the power of the educational influence of art is very considerable. It increases and moulds human abilities, gives a certain direction to the process of the formation of personal characteristics.

The power of the educational influence of different directions of art is well known. Therefore, because of widely spread trend, the pupils are given knowledge about different directions of art at school with the purpose to elaborate in pupils a strive towards esthetic values and reach the desirable level of education.

This direction seems to be natural and optimal. That is why the school dutifully follows it; however, even general observation of the teaching process makes it obvious that the rightness of the way does not mean anything unless the content, methods and rules to pass this way are in full compliance with the nature of direction.

It also proves the fact that knowledge of the theoretical-practical material determined by the teaching programmes (subjects of the aesthetic cycle) for the schools does not often create a base for esthetic education.

Even more, sometimes the process of teaching art does not affect a general cultural-esthetic level of a pupil. This is caused by the fact that in the process of teaching art a specific nature of the later as well as a nature of its participation in esthetic education is forgotten.

It is known that esthetic education condenses rational, cognitive, visional and, the most important, esthetic-emotive indicators of a person. Their consolidation much depend on the correct provision of art to a pupil with the consideration of the typical emotive specifics and a pupil's age or his/her individual abilities.

The process of teaching art logically links with education objectives when it advances development, when it is oriented on the nearest zone of education; or when education and development are considered to be two sides of one process where a pupil develops in the process of teaching.

Traditionally, pedagogics starts the teaching process mainly with rational, cognitive aspect in order to achieve educational objectives, however, it is still possible, both theoretically and practically, the cognitive aspect to be preceded with the emotive one. This point of view is well explained by V.A. Sukhomlinski who says that "It is impossible to provide successful and even normal teaching without emotive means" [1]. These words of a well known pedagogue should concern mostly teaching of the esthetic cycle as far as in this case there are more opportunities to call up emotive elements. However, as the practical observation showed this priority of art mostly remains unused.

As a rule, the subjects of the esthetic cycle are taught with the same principles, methods and rules as any subject of science. This opposes from the very bases the specific nature of artistic education and development. That is why in the pedagogical literature of the recent years creation and advancement of the united system of esthetic education as well as the issues of improvement of teaching of the subjects of esthetic cycle are widely discussed.

The special attention is given to the content of the teaching curriculum and alimentation of contradictions about these subjects among the modern scientific levels. This type of work maximally approximates the teaching practice of the separate subjects to the desirable level; however, talking about the final results is still early. Many principle issues are to be better considered and finalized.

\section{Literature Review}

High purpose and educational power of art was noticed by thinkers long ago. Already ancient Greeks were perfectly knowledgeable that the emotional world of art contains great opportunities of influencing man.

Plato was always highlighting that art should create the load which would overweight the physical or other characteristics gained from other activities, through this a human being will become harmonious and better.

Aristotle considered that education of human through art is the best means of purifying a person 
from viciousness.

Greek philosophers created a number of treatises in which the role of art, including poetry, music and painting, in influencing human beings, ennoblement of the society and establishment of better ideals is stressed.

The Middle Ages, unfortunately, could not continue the traditions of the Classical period. This was above all due to the religious-ideological world outlook, however, the power of art and its possibilities of influencing man were understood at that time too. Exactly this explains that the Middle Ages created and gave final form to many styles and trends in art.

The attitude to art is special in the period of Renaissance and the age of Enlightenment, when man again returned to the Classical ideals of harmony and beauty. At that time art became the necessary condition for the perfection of a person, his harmonious development. Since then the people began to care for the creation of certain pedagogical systems, which found its continuation in subsequent centuries and continues to the present day.

Analysis of the past historical experience reveals that despite of the recognition of importance of upbringing a human being through usage of artistic and esthetic methods and in general art, mankind still could not find the universal measures to raise a harmonious person.

Therefore, on each historical stage a mankind gets satisfied with striving for maximum realization of opportunities. At the same time, it tries to preserve everlasting indicators that have always been aspiration objects. One of the mentioned objects is an artistic taste, a personal feature of a human, formation of which is achievable via art.

In the history of philosophy, a problem of directing a person taste towards the esthetic values was comparatively fully discussed by I. Kant. Initially, he considered that taste is the sphere of individual expression. According to him, there are as many tastes as human beings; therefore, it is impossible to elaborate a scientific vision about the infinite private modifications.

According to I. Kant, science will never be able to explain why a person likes or dislikes any artistic work. However, I. Kant changed his position soon and created philosophical- systemic vision about taste stating that though science might not be able to explain why we like or dislike an artistic work, it can explain what is beautiful and what we should like. This kind of scientific vision was well defined by I.
Kant in his work "Critique of the Power of Judgment" where he also discusses his favorite and well known expression "Genius without taste and taste without genius”. I. Kant believes that a genius can only give wide material for beauty art; however, its formulation requires talent raised by the school. In order to give a certain form to an artistic work there is a great necessity of taste, which after being trained and developed will be adopted to the work. [2]

Definitely, we have neither opportunity nor necessity to fundamentally analyze a difficult philosophical concept of I. Kant on taste. We just state that according to I.Kant, taste is human ability that should be trained and exercised from school even in case of geniuses.

In N.L. Stolovich's view, "good taste is not an inherent ability of a human being. Taste takes shape in aesthetic practice and its formation depends on the aesthetic education". [3]

Thus, artistic taste may come under cultivating influence, which of course increases even more the significance of the educational-training process.

\section{Research Rationale}

As is known, the purpose of aesthetic education is the formation of a person's system of aesthetic relations. Taste occupies a special place in this system.

The philosophical sciences assign aesthetic relations to the sphere of the dialectical relation of the personality of a human being to the phenomena of the surrounding world, the expression of the active emotional evaluative reactions toward it.

It is widely believed that the aesthetic relationship of man to reality takes shape on the basis of the social- historical practice, due to which, it may be considered as the result of the historical process of the development of the world. This circumstance gives grounds to conclude that the aesthetic relationship is a human phenomenon, as it is characteristic only of man, has the concrete- historical content and obeys the dialectical process of development-perfection. With its perfect form the aesthetic relationship is revealed in the sphere of art, where the full coincidence of the emotional and the rational, the sense and reason activity occurs.

According to A. Burov "Aesthetic relationship cannot exist without an aesthetic object. The latter is the necessary condition of its existence.” [4] 
The same may be said about the subject of the aesthetic relationship, for in the conditions of the existence of man, the structures of his consciousness, the aesthetic relationship would have even been out of the question. Therefore, the aesthetic relationship, as the development of the general form of man's emotional-aesthetic orientation to reality, definitely needs the development of aesthetic consciousness. The latter has a complex content structure and represents one of the component elements of social consciousness.

According to the tradition, prevalent in Georgia, two mutually complementing approaches have been widespread in the study of social consciousness gnoseological and sociological. When identifying the interrelations between them, A.K.Uledov notes that the first one "enables us to identify the path from reality to consciousness, as a result of which ideas, views will be discovered, whereas the second, i.e. the sociological way opens up the mechanism of movement from life to reality, as a result of which the ideas and views are realized in social life." [5] Forms of social consciousness have historical character and each of them is based on reality.

The specific characteristic of aesthetic consciousness is expressed in the fact that it is of the emotional-evaluative nature. Indeed, without the latter, the creation of any aesthetic value, artistic reflection and perception of reality are inconceivable.

The observation of a quite wide range of the components of aesthetic consciousness confirms that they have many uniting and intersecting points. Among them is the phenomenon of taste, without which not a single aesthetic reaction can be presented in its full form.

The factor of taste certainly is involved in the aesthetic activity of any kind - whether perception, evaluation, receipt or non-receipt of a piece of information, wishing something, and the like. Along with this, it does not matter at all whether or not the taste in this case is developed, high, exemplary, or on the contrary, is undeveloped and needs to be changed.

The main point is that it is the necessary element of aesthetic reactions. This poses before the pedagogical educational processes the urgent need for the facilitation of development of aesthetic taste, its transformation from the initial, undeveloped state to a qualitatively higher stage. On this way, it is necessary to load the aesthetic consciousness with relevant information, to refine and perfect its certain taste.

In the special literature the word-combination "aesthetic taste" and "artistic taste" are used in parallel. At the same time, it is obvious that the concept "aesthetic taste" is much wider and includes the sphere of "artistic taste" as well. Specialists correctly consider that the concept of "artistic taste" is more adjusted to the sphere of art, and it should be discussed exactly in this regard. In $\mathrm{V}$. Skatershchikov's view artistic taste is selfsame aesthetic taste, but in the sphere of artistic work.

The demonstration of taste, as one of the basic characteristics of a personality, shows that the regularities of its development must obey the general logic of the development of the personality. The process of the education-development of the personality by means of art cannot be an exception in this respect either. Upon the very first contact with works of art, a person has a certain emotional reaction, as a result of which the desire emerges to be attracted to it or, on the contrary, to draw back.

\section{Analysis of Findings}

Man, as a rule, has a system of certain aesthetic views. At the same time, in some cases it is based only on the sensual-emotional experience, and is sometimes formed on the basis of certain knowledge and beliefs.

The aesthetic evaluation of an uneducated person is usually simple and is based only on the sensual reactions, whereas in the conditions of relevant artistic-aesthetic education, the evaluation is firmer and is distinguished by the high level of reliability.

Sense, as a certain condition of expression of aesthetic relationship, may fail to raise to genuine aesthetic sense if it has no relevant practice, is not often repeated and reinforced. Although, a person has certain inherent abilities in this direction, this is not sufficient.

Relevant practical experience, systematic contact with the respective environment, training of the abilities of sense and reason are necessary. A person is not born with ready-made aesthetic senses and taste; he only has the possibility of development of such abilities. In order for this possibility to become real, systematic direct contact with aesthetically valuable objects and phenomena are necessary.

The above mentioned, if shared, is in direct relation with the process of teaching and education, as exactly at that time a teenager may have systematic aesthetic practice, with various forms of its expression. The correct and consecutive direction of 
this process will avert many difficulties and what is the most important; will create a firm foundation for the harmonious development of a person, which will cultivate in him correct aesthetic orientations, systems of discussion and evaluation.

As is known, aesthetic evaluation as a process is preceded by the act of relevant perception. Without perception the matter will not arrive to evaluation, as they logically derive from one another.

In Prof. S. Chkhartishvili's view, objects and phenomena of reality, due to the fact that they exert influence on our organs of sense, are reflected in the consciousness in the form of perception. Therefore, perception is one of the basic sources of the accumulation of our consciousness, experience and knowledge. Knowledge and ideas, no matter with what they are linked, whether personal experience or a matter of social-state significance, without doubt and unconditionally begin exclusively from perception. [6]

Thus, it is clear that in the process of perception a person notices and perceives not only the outward qualities of objects, but cognizes material values as well.

Two main forms of perception are identified in psychological literature. These are: cognitive and emotional-evaluative perception. If in the first case dimensions of objects and phenomena, valuable as to content, are important, in the other case, i.e. at the time of aesthetic perception, the sensory data of objects and phenomena play a special role. This is due to the fact that aesthetic perception without relevant emotional sensual background loses its form. The condition of art in this regard is special, which not only merely reflects but also emotionally cognizes and interprets the realities of the surrounding world.

Thus, in the perception of a work of art the emotional principle finds the fertile ground in the inner structure of the object itself. This of course does not mean that as we are dealing with similar objective phenomena, aesthetic perception too will assume its final form mechanically, without any effort. Correct pedagogical working is necessary in order to acquaint teenagers from the very beginning with the difficulties of the process of aesthetic perception, inner dynamics, in order to give a proper direction to the development process, “artistically perfect perception of art is an active process, furthermore, "habit", which must be studied", - well-known psychologist B. Teplov notes.[7]

Specialists of the theory of artistic education consider that the concern for the development of the ability of aesthetic perception, as a principle, is a necessary condition for the cultivation of a teenager's taste.

Although, in the studies of pedagogical profile the ability of aesthetic perception is represented as the basis for the development of aesthetic consciousness, it is also noted that the process of artistic development cannot stop at this level.

The concern for the development of perception should be accompanied by the work for broadening of the horizons of aesthetic education, development of aesthetic senses, fantasy, interests and requirements.

Perception and relatively correct evaluation of the examples of art work requires a practical experience from the side of a teenager. On the bases of past contact of a teenager with the different directions of art or the examples of art teenager should have a certain level of knowledge, resource for evaluative judgment through an usage of the above mentioned teenager could express a certain position whether he/she likes an art work or not.

Practical observation of behavior, action and judgment of teenagers testifies that they possess a certain experience. However, experience is so poor and knowledge is so limited and unsystematic that teenagers' evaluation represents only expression of impression and does not go beyond the immediate reaction.

Therefore, it is necessary to elaborate such methodological aspects of perception and evaluation of art work that will enable teenagers to better interpret them.

The issue is not a new challenge for the theory of pedagogics. It is a long time since a work on the mentioned problem started separately for different age-groups. The analysis of existed experience proves that a work on this type of methodology should depend on development of knowledge and behavior of pupils, learning of recourses for evaluative judgment, development of habit of perception of form and content as a whole of the art work as well as realization of trends of stylistic elements. Peculiarities that should later be formed as personal habits and indicators can be achieved only as a result of successive work under purposeful pedagogical guidance.

We got interested whether the above mentioned thesis is elaborated, perceived and considered in the teaching documents and methodological literature by pedagogical theory in the process of teaching fine arts. 
Unfortunately, the recommendations given by the scientists do not attain at all or are reflected in the school documents very late, which has become a traditional defect of school work practice. Accordingly, the recommendations are not effectively used on the level of practical work at school. Teaching fine arts at school is not an exception. In the process of teaching this subject, the main attention was directed towards the process of implementation of the practical work by the pupils.

A practice of theoretical relation with the arts, which is vitally important for the development of the certain directions of esthetical consciousness of a teenager, has always been scantily considered in the whole structure of teaching activities. Among the other reasons, one was caused by the fact that the teaching documentation was taken from the union analogies; therefore, it was following the trends being considered important by the Soviet Union. Though there were small differences among the school documentation of different soviet countries, the difference was on one hand very insignificant and on the other hand not having a progressive nature. The fact is not surprising as far as theoretical-practical school for esthetic and artistic education was established in Georgia much later than in Russia.

Painting, graphics, sculpture, architecture, democratic-applied art examples, and the process of drawing-modeling or appliqué work leaves indelible trace on esthetic consciousness, perception and sensor activities of a teenager.

Observation of the practices at schools proves that, unfortunately, the above mentioned opportunities of fine arts are not fully applied in the teaching process.

One of the reasons is that the teachers at the lesson of fine art are mostly busy with the practical process of drawing and pay less attention to the conversation about art, objectives to organize perception of art, esthetical comparison, consideration-judgment and the related issues. If on the elementary level it is still possible to do, it is absolutely necessary to widen the activities for perception of arts for teenagers. Of course, this must be done in parallel with artistic activities as far as the practice of artistic education proves that the artistic activities develop the high level of formation of skill of perception in teenagers.

Therefore, involvement of a teenager in a practical work with the objective to develop skill of perception is pedagogical obligation. However, the main concern is what should be correlation of time allotment.

According to the practice existing till now, perception of art is given only one third of teaching time (sometimes not even that). This type of allotment of teaching time is not scientifically proved. At all levels of studies, practical work is comparatively exaggerated with the primitive of drawing.

Thus, it is necessary to highlight the process of perception. This requirement, of course, rests upon the psychological and pedagogical bases. It is determined that on the bases of intensified practical work at the elementary level, at the Grades IV-VI, creation of psycho-physical background necessary for theoretical practice of fine arts is basically finished. This intensifies the interest towards visible objects of the surrounding, the language specific to art and beauty existing in nature and society. A strive of pupils towards authoritative judgment about art is also strengthened. Despite of the fact that a massive inclination towards drawing is gone, teenagers have a willingness to know more and be able to do more about art, which increases endeavor to develop professionally. If a pupil from elementary level expresses his/her impression about art precipitately a teenager is more cautious. In a teenager's works or judgment one can decipher eagerness towards analytical thinking.

All mentioned above emphasizes a necessity to increase time allotment to conversations about art with teenagers. At the same time, the conversation should not be just a mere talking but the one loaded with the content of art criticism in order to deliver to a teenager informational-analytical material and prepare for emotional-esthetic judgment.

For full realization of educational opportunities of fine art in teenagers, it is necessary to a brief but emotively attractive and informative conversation about the topics that are: "what is fine arts?", "what are the expressive means in fine arts?", what are composition, color and use of color?” Also, a teacher should talk with teenagers about architecture as example of art, plastics in architecture, epoch and style, etc. These types of conversations should be conducted at the lessons as well as outside class or school activities. These types of conversations are especially impressive and effective after the fourth grade as far as at this age pupils can better understand and realize what is said and notice causal- consequent links among the facts. It is also important to bring the 
parallels with historical, cultural, literal and music material considered under the school curriculum.

A completely new stage in the practice of teaching of fine arts is the national curriculum worked out by the Ministry of Education and Science of Georgia in 2007 and the place of fine and applied arts in this curriculum, where the educational function of the subject is brought to the forefront. [8]

The introduction of this subject allows us to engage pupils in creative and interpreting activity, and in this way to cultivate imagination and the ability to experience beauty, to arouse constant interest and love for art, to familiarize them with national and world cultural values means of fine arts.

Fine and applied arts has become a diverse and interesting phenomenon nowadays. It has followed a long path of development. The process is not completed yet, much remains to be identified.

Naturally, such a broad formulation of the task, dictated by the requirements of time, outlines new prospects of teaching this subject. Without the ability of aesthetic perception of reality and phenomena, a person, unassisted by others, will not manage to perceive and evaluate one or another work of art in its unity. At best this process ends in the understanding of the plot of the work, its content aspects, which cannot be regarded as the full comprehension of art.

The intensification of the section of perception in the curriculum also finds its argumentation in the circumstance that in modern conditions the goals and objectives of teaching of fine arts at school is more real.

Teachers are well aware that they are not educating painters at school. Their obligation is to care for the general development of pupils, which cannot be achieved by one-sided work in painting proper. All components of painting (painting, sculpture, decorative-applied activity, perception, etc.) complement and enrich one another. At the stage of the given age now one component is in the forefront, now another, such alternation of components is dictated by the character of the prevailing form of a child's behavior at a particular age.

In the alternation of separate components of the subject in the teaching content, the logic of the component alternation, peculiarities of the social and natural environment, etc. should be taken into account. Therefore, the forms of teaching activities alternate throughout the entire curriculum. However, not only the form changes, but the functional direction of separate forms too.

\section{Conclusions}

The above-mentioned, in my view, gives grounds to note the following:

A problem of development of artistic taste in teenagers should be presented within the system of esthetic education which needs a complex approach and consideration of its all basic parameters.

A correct organization of theoretical work on art is a measure to develop artistic taste in teenagers through fine arts. A certain importance to this process is given to practical creative activity; however, the most important is the theoretical work with the examples of fine arts. In this process widening of an esthetic horizon of a teenager, gaining knowledge, development of ability to analyze and evaluate art work, enhancement of emotive esthetic world take place.

A necessary pre-condition to develop an artistic taste in a teenager is realization of teenagers' approach towards the art work, gradual change of established system of vision fixed as a general feeling by means of an introduction of the new values to the level of consciousness.

It is necessary to organize researches which would impart new content to the process of development, and for this purpose would uncover the reserves still existing in the form of interrelations of personal-psychological characteristics of adolescence and inner possibilities of fine arts, as a teaching discipline. Such an approach will enable us to find methodologically proper ways of pedagogical guidance for the development of pupils' artistic taste by means of fine arts.

\section{References}

[1] Sukhomlinski, V. Birth of a Citizen, Moscow, 1971, p. 247

[2] Kant I. "Critique of the Power of Judgment", Moscow, 1965, Vol. IV p.325

[3] Stolovich, L. Nature of Aesthetic Value. Moscow, 1972, pp. 212-213.

[4] Burov, A. Aesthetics: Problems and Judgment. Moscow, 1975, p. 50.

[5] Uledov, A. The Structure of Public Consciousness. Moscow, 1968, pp. 35-36. 
International Journal for Cross-Disciplinary Subjects in Education (IJCDSE), Volume 3, Issue 4, December 2012

[6] Chkhartishvili, S. Pedagogical Psychology. Tbilisi, 1975, volume 1, p. 47.

[7] Teplov, B. Psychological Issues of Artistic Education. Moscow. RSFSR Pedagogical Science Academy Messenger, 1947, 11.

[8] The Ministry of Education and Science of Georgia The National Curriculum, Tbilisi, 2007. 